\title{
VEGF isoforms have differential effects on permeability of human pulmonary microvascular endothelial cells
}

\author{
Khadija Ourradi ${ }^{1}$, Thomas Blythe ${ }^{1}$, Caroline Jarrett', Shaney L. Barratt ${ }^{1}$, Gavin I. Welsh ${ }^{2}$ and Ann B. Millar ${ }^{1 *}$
}

\begin{abstract}
Background: Alternative splicing of Vascular endothelial growth factor-A mRNA transcripts (commonly referred as VEGF) leads to the generation of functionally differing isoforms, the relative amounts of which have potentially significant physiological outcomes in conditions such as acute respiratory distress syndrome (ARDS). The effect of such isoforms on pulmonary vascular permeability is unknown. We hypothesised that $V_{E G F_{165}}$ and $V_{E G F}{ }_{165} \mathrm{~b}$ isoforms would have differing effects on pulmonary vascular permeability caused by differential activation of intercellular signal transduction pathways.

Method: To test this hypothesis we investigated the physiological effect of VEGF ${ }_{165}$ a and VEGF ${ }_{165} \mathrm{~b}$ on Human Pulmonary Microvascular Endothelial Cell (HPMEC) permeability using three different methods: trans-endothelial electrical resistance (TEER), Electric cell-substrate impedance sensing (ECIS) and FITC-BSA passage. In addition, potential downstream signalling pathways of the VEGF isoforms were investigated by Western blotting and the use of specific signalling inhibitors.

Results: VEGF $_{165}$ a increased HPMEC permeability using all three methods (paracellular and transcellular) and led to associated $\mathrm{VE}$-cadherin and actin stress fibre changes. In contrast, $\mathrm{VEGF}_{165} \mathrm{~b}$ decreased paracellular permeability and did not induce changes in VE-cadherin cell distribution. Furthermore, VEGF 165 a and VEGF $165 \mathrm{~b}$ had differing effects on both the phosphorylation of VEGF receptors and downstream signalling proteins PMEK, p42/44MAPK, p38 MAPK, PAKT and peNOS. Interestingly specific inhibition of the PMEK, P38 MAPK, PI3 kinase and eNOS pathways blocked the effects of both $\mathrm{VEGF}_{165}$ a and $\mathrm{VEGF}_{165} \mathrm{~b}$ on paracellular permeability and the effect of $\mathrm{VEGF}_{165}$ a on proliferation/migration, suggesting that this difference in cellular response is mediated by an as yet unidentified signalling pathway(s).
\end{abstract}

Conclusion: This study demonstrates that the novel isoform $\mathrm{VEGF}_{165}$ a and $\mathrm{VEGF}_{165} \mathrm{~b}$ induce differing effects on permeability in pulmonary microvascular endothelial cells.

Keywords: Vascular permeability, Vascular endothelial growth factor (VEGF), Cell signalling

\section{Background}

VEGF was originally identified by its properties as both a permogen and a mitogen, key elements in the function of the alveolar-capillary membrane, leading to interest in its role in many forms of lung disease particularly ARDS [1-3]. We and others found that VEGF levels were compartmentalised between the alveolar space and the vascular bed $[4,5]$. Low levels of intrapulmonary VEGF

\footnotetext{
* Correspondence: ann.millar@bristol.ac.uk

${ }^{1}$ Academic Respiratory Unit, School of Clinical Sciences, University of Bristol, Bristol, UK

Full list of author information is available at the end of the article
}

were found in patients with ARDS with increasing intrapulmonary VEGF levels associated with recovery [5]. In contrast, plasma levels in patients with ARDS were elevated compared with normal, at-risk, or ventilated control subjects, with falling levels associated with recovery [6]. These data suggest that VEGF is beneficial in the alveolar space but detrimental in the vascular space. To explore the significance of these observations, it is necessary to understand the mechanisms that regulate VEGF bioactivity. VEGF exerts its biological effect through specific receptors, VEGF-R1 and VEGF-R2 and co-receptors, neuropilin-1 and neuropilin-2 [7]. In addition, alternative 
splicing of VEGF transcripts leads to the generation of several functionally different isoforms $[8,9]$. We have previously explored changes in $\mathrm{VEGF}_{x x x}$-isoforms and receptor expression as mechanisms for regulating VEGF bioactivity and suggested that both these factors may contribute [10] but do not fully explain the reported contradictory findings. The $\mathrm{VEGF}_{\mathrm{xxx}} \mathrm{b}$ isoform family consists of peptides of the same length as other forms but with a different Cterminal six amino acids-SLTRKD rather than CDKPRR [11]. The receptor binding and dimerisation domains are intact, but VEGF ${ }_{x x x} b$ stimulates a unique pattern of VEGFR2 tyrosine residue phosphorylation, contrasting with those activated by conventional isoforms [9]. Two specific isoforms, VEGF ${ }_{165} \mathrm{a}$ and $\mathrm{VEGF}_{165} \mathrm{~b}$ isoforms were shown to have contrasting effects on the epithelial and endothelial sides of the alveolar-capillary membrane [12]. These data suggest a pneumotropic effect which could be beneficial within the alveolar space following ARDS. However, the effect of these isoforms on vascular permeability another key element of ARDS is unknown.

We hypothesised that $\mathrm{VEGF}_{165} \mathrm{a}$ and $\mathrm{VEGF}_{165} \mathrm{~b}$ activate different signalling pathways mediating cell permeability, a potential explanation for the conflicting observations on effects in the vascular space. To explore this theory, we used three methods of assessing vascular barrier function and found contrasting effects with $\mathrm{VEGF}_{165}$ a increasing permeability and $\mathrm{VEGF}_{165} \mathrm{~b}$ decreasing permeability. We then explored the relationship of downstream pathways to these functional differences. We compared the effects of specific signalling pathway inhibitors of MEK/p38MAPK/ PI3K and eNOS on permeability, cell migration and proliferation to identify a mechanism by which increased permeability could be resolved whilst maintaining beneficial cell proliferation and migration.

\section{Methods}

A detailed description of materials and methods is given in the online data supplement.

\section{Primary cell culture}

Human Pulmonary microvascular endothelial cell (HPMEC) cryopreserved from passage 2 (PromoCell, Heidelberg, Germany) were cultured in endothelial cell basal medium MV2 (C-22221, PromoCell, Germany) complemented with supplement pack (C-39221, PromoCell, Germany) according to manufacturer's instructions.

For all experiments cells were grown to $80 \%$ confluence, quiesced (MV2 media only) and stimulated with combinations of VEGF 165 a and $\operatorname{VEGF}_{165} \mathrm{~b}(20 \mathrm{ng} / \mathrm{ml}$ as considered physiologically relevant in circulating plasma) $[4,6]$ in the presence or absence of specific signalling pathway inhibitors (U0126, SB203580, LY294002 (Cell Signalling, UK) or L-NAME (Calbiochem, UK).

\section{Measurement of TEER by Endohm}

Measurement of trans-endothelial electrical resistance (TEER) of the cell monolayer was performed using an Endohm 12 electrode chamber and an endothelial volt/ ohm meter EVOM $^{2}$ (World precision Instruments, USA) as previously described by Bevan and al [13].

\section{ECIS}

Cells were plated at 20000 cells/cm2 into 8-well arrays (8W10E+; Wolf laboratories Ltd). Data was automatically and continuously collected every 2 min and recorded by computer. Experiments were performed after cells reached confluence with basal TEER values $>1500 \mathrm{~Hz}$.

\section{FITC-BSA passage}

Transendothelial permeability to macromolecules was assessed by the passage of FITC-conjugated BSA (relative molecular mass 66,000) across cell monolayers in tissue culture inserts as previously described [14].

\section{Scratch assay (Migration and proliferation)}

Cells were seeded with $100 \mu \mathrm{l}$ of cell suspension $\left(5 \times 10^{5}\right.$ cells $/ \mathrm{ml}$ ) in an Ibidi culture-chamber (Ibidi GmbH Munich, Germany). Cells were pre-incubated with or without inhibitor for 1 hour before removal of the chamber. Cells were then incubated in MV2 medium alone or MV2 medium with $20 \mathrm{ng} / \mathrm{ml}$ of recombinant protein $V G_{165} \mathrm{a}$ or $\mathrm{VEGF}_{165} \mathrm{~b}$. Images were captured and analysed at 0 and $24 \mathrm{~h}$.

\section{Western blotting analysis}

Cell lysates were separated on sodium dodecyl sulphatepolyacrylamide gel electrophoresis (SDS-PAGE) and immunoblotted. Blots were blocked with $5 \%$ bovine serum albumin (BSA) (Fischer Scientific UK,) and incubated overnight at $4{ }^{\circ} \mathrm{C}$ with primary antibodies

\section{Immunocytochemistry}

HPMEC were stimulated with $100 \mathrm{ng} / \mathrm{ml}$ of $\operatorname{VEGF}_{165} \mathrm{a}$, $\mathrm{VEGF}_{165} \mathrm{~b}, \mathrm{VEGF}_{165} \mathrm{a}+\mathrm{b}$ or without any stimulation (control) for $10 \mathrm{~min}$. They were then fixed, permeabilised and immunostained for VE-cadherin (Sigma, UK) and Alexa Fluor 568 Phalloidin (Invitrogen, UK) for staining actin structures.

\section{Results}

VEGF $_{165} \mathrm{a}$ increases and $\mathrm{VEGF}_{165} \mathrm{~b}$ decreases permeability in HPMEC

A number of techniques have been described to assess endothelial barrier function [15]. The barrier properties of endothelial cell junctions can be directly measured by TEER that has been shown to be indirectly correlated with both adherens and tight junctions within a confluent monolayer $[16,17]$. We measured the TEER of HPMEC 
monolayers. VEGF ${ }_{165}$ a significantly reduced the cell resistance (increased permeability) $* p<0.01$, from $45 \mathrm{~min}$ onwards, in contrast, VEGF $_{165}$ b significantly increased resistance (decreased permeability) $* *<0.01$ between 15 to 45 min compared with unstimulated control cells (Fig. 1a).

ECIS was utilised as another method to evaluate the effect of VEGF isoforms on cell permeability. A similar response to that seen using the Endohm system was observed for HPMEC. VEGF 165 a induced an increase in cell monolayer permeability $(* * * 0<0.001)$ in contrast to VEGF $_{165} \mathrm{~b}$ which induced a significant decrease $(* p<0.05)$ in the cell monolayer permeability (Fig. 1b).

The last experimental technique used to assess permeability was FITC-coupled BSA passage. The permeability of the HPMEC monolayer for FITC-BSA was monitored every $15 \mathrm{~min}$ up to $90 \mathrm{~min}$ by measuring the fluorescence intensity of the medium in the lower compartment. For unstimulated control cells, the level of BSA in the lower compartment increased slowly over time in a comparable manner to those treated with $\mathrm{VEGF}_{165} \mathrm{~b}$; no significant difference was observed between them in HPMEC (Fig. 1c). When the cells were cultured in the presence of $\mathrm{VEGF}_{165} \mathrm{a}$, a significant $(" p<0.05)$ timedependant increase in BSA permeability was detected after $45 \mathrm{~min}$ and persisted for at least $90 \mathrm{~min}$, suggesting an increase in the cell monolayer permeability.

\section{VEGF $_{165}$ a induces changes in VE-cadherin distribution pattern and actin stress fibres in HPMEC compared to VEGF $_{165}$ b}

Changes in cell permeability are closely related to changes in the cell-cell junction structures [18]. We went on to analyse potential cytoskeleton remodelling induced by VEGF isoforms. VE-cadherin has been particularly associated with endothelial cell adherens junctions but may also contribute to change in tight junction activity $[19,20]$.

\section{a}

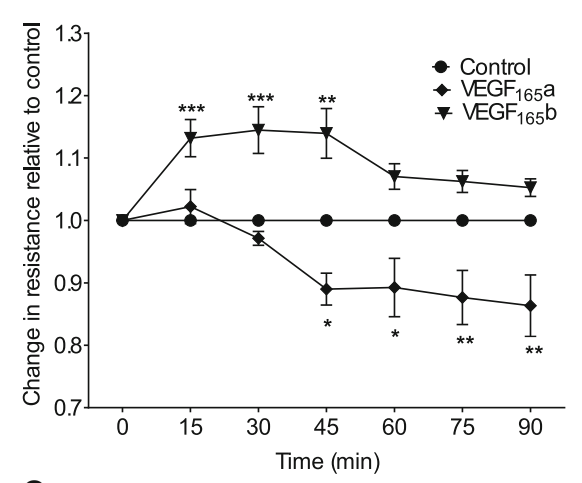

C

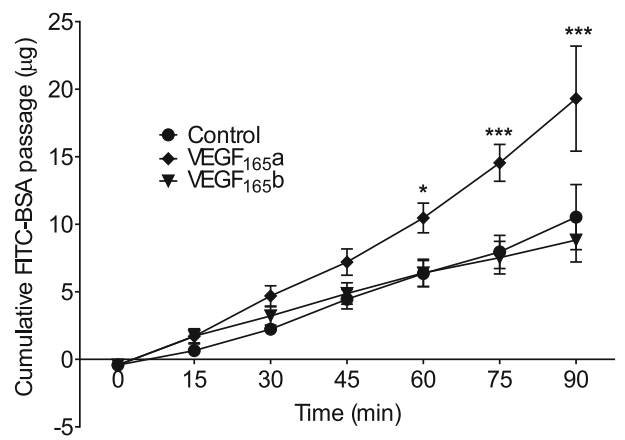

\section{b}

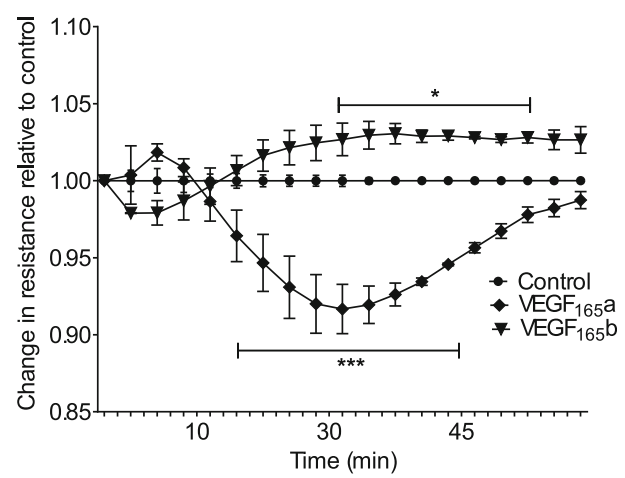

\footnotetext{
Fig. 1 HPMEC stimulated with $20 \mathrm{ng} / \mathrm{ml}$ of VEGF ${ }_{165} \mathrm{a}, \mathrm{VEGF}_{165} \mathrm{~b}$ or without any stimulation (control). a Paracellular permeability was quantified by TEER using endohm-12 system in HPMEC cultured in inserts. VEGF 165 a reduced resistance (increased permeability) ${ }^{*} p<0.05$ (45 min onwards) and VEGF $_{165} \mathrm{~b}$ increased resistance (decreased permeability) ${ }^{* *} p<0.001$ (15 to $45 \mathrm{~min}$ ) compared to control. $\mathbf{b}$ ECIS measurements on HPMEC show that $\mathrm{VEGF}_{165}$ a reduced the resistance (increased permeability) significantly ${ }^{* * *} p<0.001$ in comparison to control; whereas VEGF ${ }_{165} \mathrm{~b}$ had an opposite effect with a significant increase $\left({ }^{*} p<0.05\right)$ in the resistance (reduced permeability). Data expressed as a mean fold-change compared to control over time. c The passage of FITC-coupled BSA across the monolayer of HPMEC was monitored over a period of $90 \mathrm{~min}$. The fluorescence intensity of the aliquots was quantified and data was expressed as cumulative FITC-BSA over time. Concentration of FITC-BSA in the lower chamber slowly increased in both control cells and those stimulated with VEGF 165 b; in contrast cells stimulated with VEGF 165 a showed a significant increase in the passage of FITC-BSA $p<0.01$ after 60 min. Each experiment was performed in triplicate $(n=5-8)$. All data were analysed using two-way ANOVA and Bonferroni post-test for multiple analysis and plotted as mean \pm SEM
} 
Previously, a changed distribution to a zig-zag pattern in VEGF $_{165}$ a treated human umbilical vascular endothelial cells (HUVEC) was demonstrated using $100 \mathrm{ng} / \mathrm{ml} \mathrm{stimu-}$ lation [20]. We repeated this experiment using HPMEC and showed similar results suggesting a significant change in VE-cadherin distribution between the cells stimulated with $V_{E G F}{ }_{165} \mathrm{a}$ (Fig. 2a). Visible gaps appeared between the cells with an apparent zig-zag pattern of VE-cadherin distribution between adjacent cells. In contrast, stimulation with the VEGF ${ }_{165} \mathrm{~b}$ isoform induced minimal change compared to untreated control cells suggesting it did not induce VE-cadherin reorganisation (Fig. 2a). In addition, changes in the actin structure were observed between the stimulated and the unstimulated cells demonstrating an increase of stress fibres across the cells and more actin filopodia with $\mathrm{VEGF}_{165} \mathrm{a}$. Again, in contrast, there was only a partial induction of actin filaments in the cell periphery and stress fibres by VEGF $_{165} \mathrm{~b}$ (Fig. $2 \mathrm{~b}$ ). These data led to the hypothesis that $V_{E G F}{ }_{165} \mathrm{a}$ and $\mathrm{VEGF}_{165} \mathrm{~b}$ activate different signalling pathways involved in permeability in HPMEC.

VEGF-R2 has been reported to induce most downstream signalling effects through the tyrosine sites tyr1175 and tyr1214 [21, 22]. These two tyrosine sites play a crucial and direct role in the recruitment of adaptor proteins that activate multiple signalling pathways such as proliferation, survival, migration and permeability $[23,24]$. Therefore, we studied VEGF isoform induced phosphorylation of those tyrosine sites in HPMECs.

\section{VEGF $_{165} \mathrm{a}$ and $\mathrm{VEGF}_{165} \mathrm{~b}$ induce differential phosphorylation of the VEGF receptors at tyrosine 1175 and 1214 in HPMEC}

VEGF-R2 phosphorylation at the tyrosine (tyr) 1175 site, was significantly induced by $\operatorname{VEGF}_{165} \mathrm{a}$ at $5 \mathrm{~min}$ and $10 \mathrm{~min}(p<0.05)$ in HPMEC (Fig. 3a) and returned to control levels at $60 \mathrm{~min}$ post stimulation. In contrast, VEGF $_{165}$ b stimulation did not induce significant phosphorylation at this site. Phosphorylation of VEGF-R2 at the tyr1214 also reached a maximum at $5 \min (p<0.01)$ with $\mathrm{VEGF}_{165} \mathrm{a}$ and subsequently decreased as represented in Fig. 3b. VEGF $165 \mathrm{~b}$ also induced significant phosphorylation of tyr1214 site at $5 \mathrm{~min}(p<0.05)$ in HPMEC, in contrast to tyr1175. These differences in receptor phosphorylation support the potential for differential binding of other adaptor proteins in addition to the previously reported changes in co-receptor binding that has been shown to contribute to VEGF-induced vascular permeability.

Having identified these phosphorylation differences we wanted to identify specific pathways leading to cell permeability which is less well characterised than those of other VEGF functional effects [7]. Further Western blotting of HPMEC was undertaken, to investigate the effect

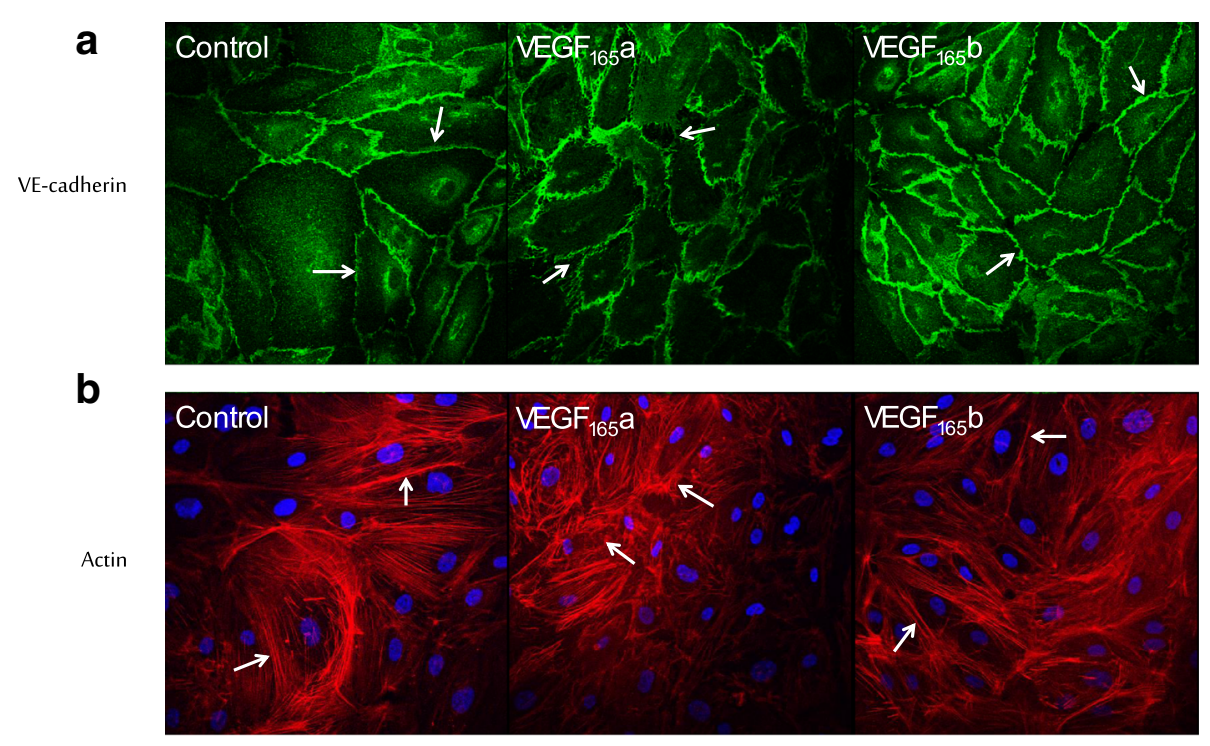

Fig. 2 a HPMEC were stimulated with $100 \mathrm{ng} / \mathrm{ml}$ of VEGF ${ }_{165} \mathrm{a}, \mathrm{VEGF}_{165} \mathrm{~b}$ or without stimulation (control) for $10 \mathrm{~min}$. Then they were fixed, permeabilised and immunostained for VE-cadherin. Control and VEGF ${ }_{165} \mathrm{~b}$ : straight and linear distribution of VE-cadherin at the cell junctions were observed (see arrows). $V_{E G F}$ as: distribution of VE-cadherin in a zig-zag pattern with the appearance of gaps between the cells (see arrows) (magnification $\times 40$ ). $\mathbf{b}$ Actin and nucleus staining in HPMEC in different conditions. Control: actin filament distributed mainly at the cell periphery between the cell-cell junctions. VEGF $165 \mathrm{a}$ : disruption of the cortical actin frame with filopodia and stress fibre formation across the cells (arrows). VEGF 165 b: mixed field with the appearance of actin at the cell periphery and visible filopodia (magnification $\times 40)$. $(n=5$, representative image shown) 

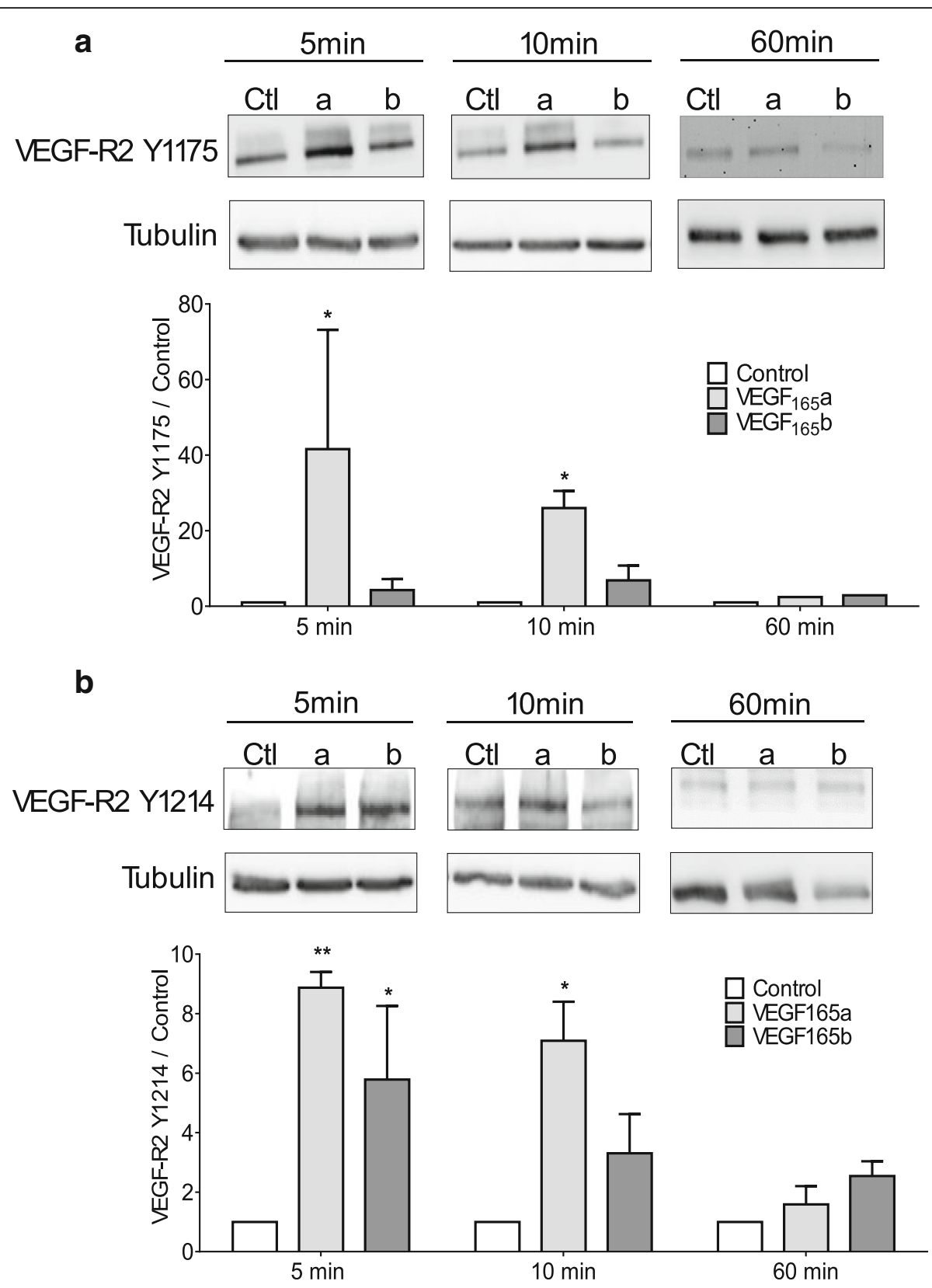

Fig. 3 Activation of VEGF-R2 was determined with a phospho-specific antibody recognising tyrosine (Y) site 1175 and site 1214 in graph (a) and (b) respectively for cells stimulated with $20 \mathrm{ng} / \mathrm{ml}$ of VEGF ${ }_{165} \mathrm{a}(\mathbf{a}), \mathrm{VEGF}_{165} \mathrm{~b}$ (b) or without stimulation (Ct). Representative Western blot showing the different conditions at 5, 10 and 60 min plus the loading control blot and densitometry $(n=5)$. All data were analysed using Kruskal-Wallis with post hoc Dunn's analysis and plotted as mean \pm SEM

of VEGF isoforms on the phosphorylation of several proteins previously suggested to be involved in specific functional downstream cellular effects. In parallel, we continued to use the Endohm assay to assess paracellular permeability and utilised the scratch assay combining both migration and proliferation processes $[25,26]$ to assess the specificity of the functional effect of individual signalling pathway inhibitors.
Specific inhibition of pMEK1/2, p42/44MAPK and p38MAPK induction by VEGF ${ }_{165}$ a and VEGF ${ }_{165}$ b in HPMEC does not have a differential effect on permeability and migration/proliferation pathways

The MEK and mitogen activated protein kinase (MAPK) pathways are among the most widely studied in VEGF biology and considered to have critical roles in cell proliferation and cell growth and differentiation [27, 28]. 
We initially sought to determine whether inhibition of these proteins would have a specific functional effect i.e. inhibit proliferation/migration but not permeability as previously suggested [29].

HPMEC showed a similar activation pattern of pMEK1/2 and p42/44MAPK proteins with an increase in the phosphorylation when treated with $V_{E G F}$ a a for 5 and 10 min that subsequently returned towards baseline at $60 \mathrm{~min}$ (Fig. 4-a\&b respectively). VEGF 165 b had a delayed effect with significant phosphorylation of both proteins occurring at $10 \mathrm{~min}$. The pMEK1/2 phosphorylation in response to VEGF isoforms showed a significant increase at 5 and $10 \mathrm{~min}(p<0.01)$ for the cells stimulated with $\mathrm{VEGF}_{165}$ a compared to control. The maximum response was observed at $10 \mathrm{~min}$ for both proteins. However, VEGF $165 \mathrm{~b}$ induced a significant increase of pMEK1/2 and p42/44MAPK phosphorylation at $10 \mathrm{~min}$ only. At $60 \mathrm{~min}$ the level of both phosphoproteins in the stimulated cells returns toward the control levels.

U0126 is a compound reported to be a highly selective inhibitor of MEK1 and MEK2 and utilised to block the classical MAPK cascade in cells that leads to cell proliferation [30]. U0126 inhibited the permeability effects of both VEGF $_{165} \mathrm{a}$ and VEGF $_{165} \mathrm{~b}$ on HPMEC (Fig. 4c and $\mathrm{d}$ respectively). $\operatorname{VEGF}_{165} \mathrm{a}$, but not $\operatorname{VEGF}_{165} \mathrm{~b}$, induced a significant increase in the cell migration into the "scratch" $(p=0.004)$ in comparison to control (Fig. 4e) that was inhibited byU0126. These data suggest that the MEK pathway is activated by both VEGF ${ }_{165}$ a and VEGF ${ }_{165} \mathrm{~b}$ but any functional divergence must occur downstream.

In addition, phosphorylation of p38MAPK was assessed as studies reported that VEGF stimulation on endothelial cells, also lead to activation of the Cdc42/p38MAPK pathway which triggers cytoskeletal modifications [31]. Similarly, to the other proteins studied, p38 MAPK phosphorylation was significantly increased by $\operatorname{VEGF}_{165} \mathrm{a}$ in HPMEC at 5 and $10 \mathrm{~min}(p<0.05)$. Cells stimulated with VEGF $_{165} \mathrm{~b}$ showed a significant increase in p38MAPK phosphorylation $(p=0.04)$ compared to the untreated cells (Fig. 5a). Nevertheless, this phosphorylation was transient and returned to baseline levels by ten minutes. SB203580 is reported to specifically inhibit the activation of SAPK2/ p38 MAPK in cell-based assays but no other related kinase protein including MAPK family members [30]. When HPMEC were incubated with SB203580 (p38MAPK inhibitor) again there was inhibition of $\mathrm{VEGF}_{165} \mathrm{a}$ and VEGF $_{165}$ b permeability effects (Fig. $5 \mathrm{~b}$ and c). Cell proliferation/migration into the "scratch" was significantly increased $(p=0.002)$ only with $\operatorname{VEGF}_{165}$ a stimulation and this effect was inhibited by SB203580 (Fig. 5d).

Having identified significant differences in the activation kinetics of MEK, p42/44MAPK and p38MAPK by VEGF $_{165}$ a compared to VEGF $_{165} \mathrm{~b}$ (that reflected changes in permeability but not specific to it alone), we then looked at the effect of VEGF isoforms on AKT also known as protein kinase $\mathrm{B}(\mathrm{PKB})$ protein. AKT has been shown to promote the proposed cell survival pathway mediated by the activation of PI3-kinase protein kinase [32] but it has been also associated with eNOS production which is closely associated with permeability [33].

\section{Specific inhibition of AKT induction by $\operatorname{VEGF}_{165} \mathrm{a}$ and VEGF $_{165} \mathrm{~b}$ in HPMEC does not have a differential effect on permeability and survival pathways}

$\mathrm{VEGF}_{165} \mathrm{~b}$ induces a rapid and robust phosphorylation of pAKT at $5 \mathrm{~min}$ and $10 \mathrm{~min}(p<0.01)$ in HPMEC with maximal AKT phosphorylation detected at $5 \mathrm{~min}$ (Fig. 5e). Stimulation with VEGF ${ }_{165}$ a also induced a significant phosphorylation of AKT at $5(p<0.05)$ and $10 \mathrm{~min}(p<0.01)$ and returned to control levels at $60 \mathrm{~min}$. LY294002 compounds is an inhibitor of phosphatidylinositol 3 kinase (PI3K) and inactivation of PI3K have been reported to lead to dephosphorylation of Akt that subsequently stop G1 cycle in cell growth and ultimately lead to cell apoptosis [34, 35]. Co-culture with LY294002 to block AKT protein inhibited both the permeability effects of VEGF 165 a and VEGF ${ }_{165} \mathrm{~b}$ on HPMEC (Fig. $5 \mathrm{f}$ and g). In contrast with the permeability assay where the cell monolayer was stable over the experiment $(2 \mathrm{~h})$, inhibition of AKT for long periods $(24 \mathrm{~h})$ induced cell death so we were unable to undertake the scratch assay as a migration/proliferation model.

Finally, we investigated the potential of the eNOS pathway for differential effects. There is a significant body of evidence to suggest that endothelial nitric oxide (synthesised by eNOS) may have a crucial role in causing hyperpermeability in response to pro-inflammatory agents such as VEGF $[36,37]$. Therefore, the effects of the different VEGF isoforms on the eNOS phosphorylation in HPMEC were studied.

\section{Specific inhibition of eNOS induction by $\mathrm{VEGF}_{165} \mathrm{a}$ and VEGF $_{165}$ b in HPMEC does not have a differential effect on permeability and nitric oxide signalling pathways}

In HPMEC, $V_{E G F}{ }_{165} \mathrm{a}$ induced a significant increase in the phosphorylation of eNOS at $5(p<0.05)$ and $10 \mathrm{~min}(p<$ 0.01) compared to untreated control cells (Fig. 6a). VEGF $_{165} \mathrm{~b}$ did not induce changes in the phosphorylation of eNOS at Ser 1177. L-NAME (NG-Nitro-L-arginine Methyl Ester, Hydrochloride) is an analogue of Larginine required for the nitric oxide synthesis by the vascular endothelium [38]. HPMEC pre-incubated with LNAME and treated with $\mathrm{VEGF}_{165} \mathrm{a}$ or $\mathrm{VEGF}_{165} \mathrm{~b}$ did not have any significant change in resistance compared to control (Fig. 6b and c). In the scratch proliferation/migration model, L-NAME inhibited the migration effect induced by $\operatorname{VEGF}_{165}$ a, but no difference was observed for 


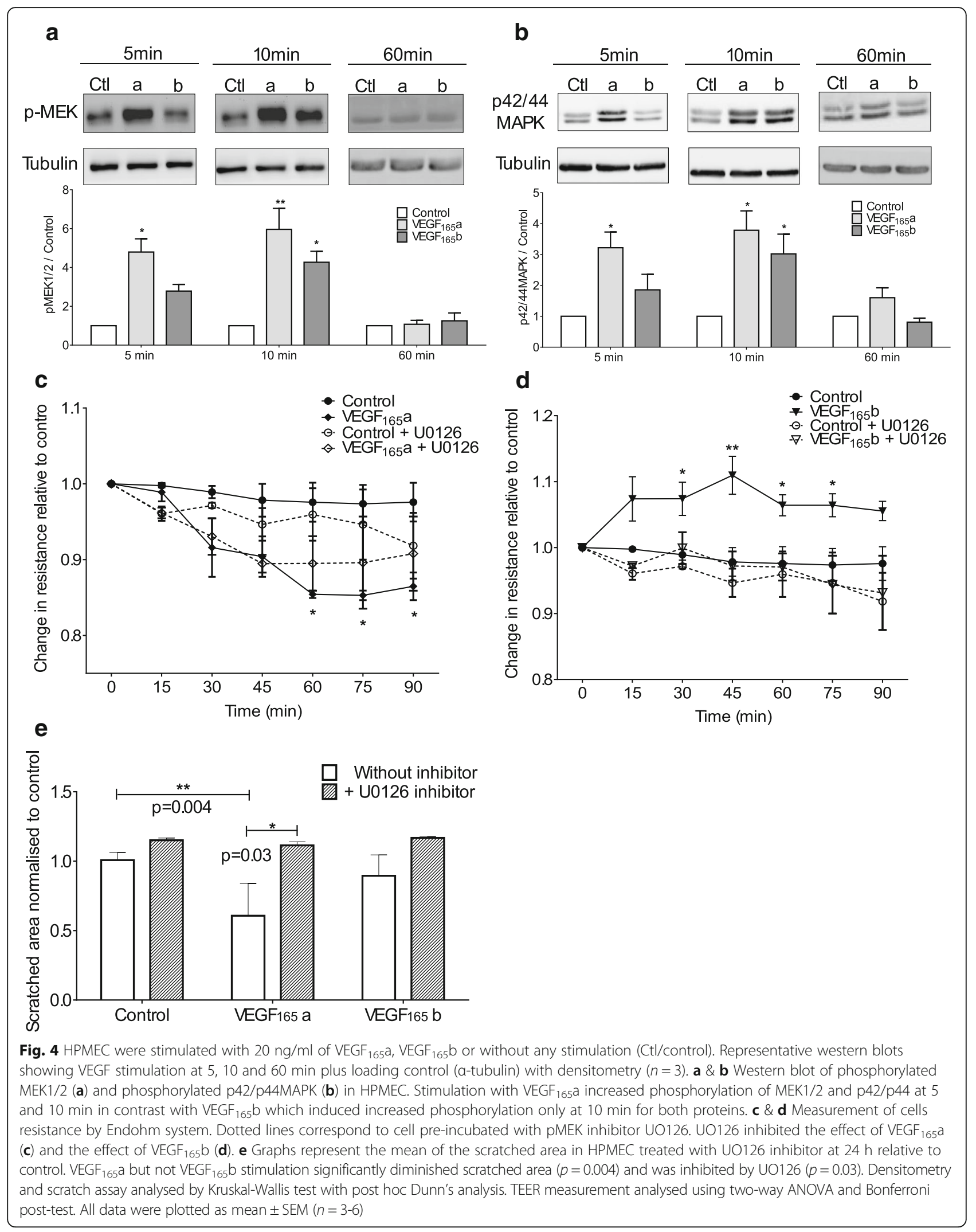




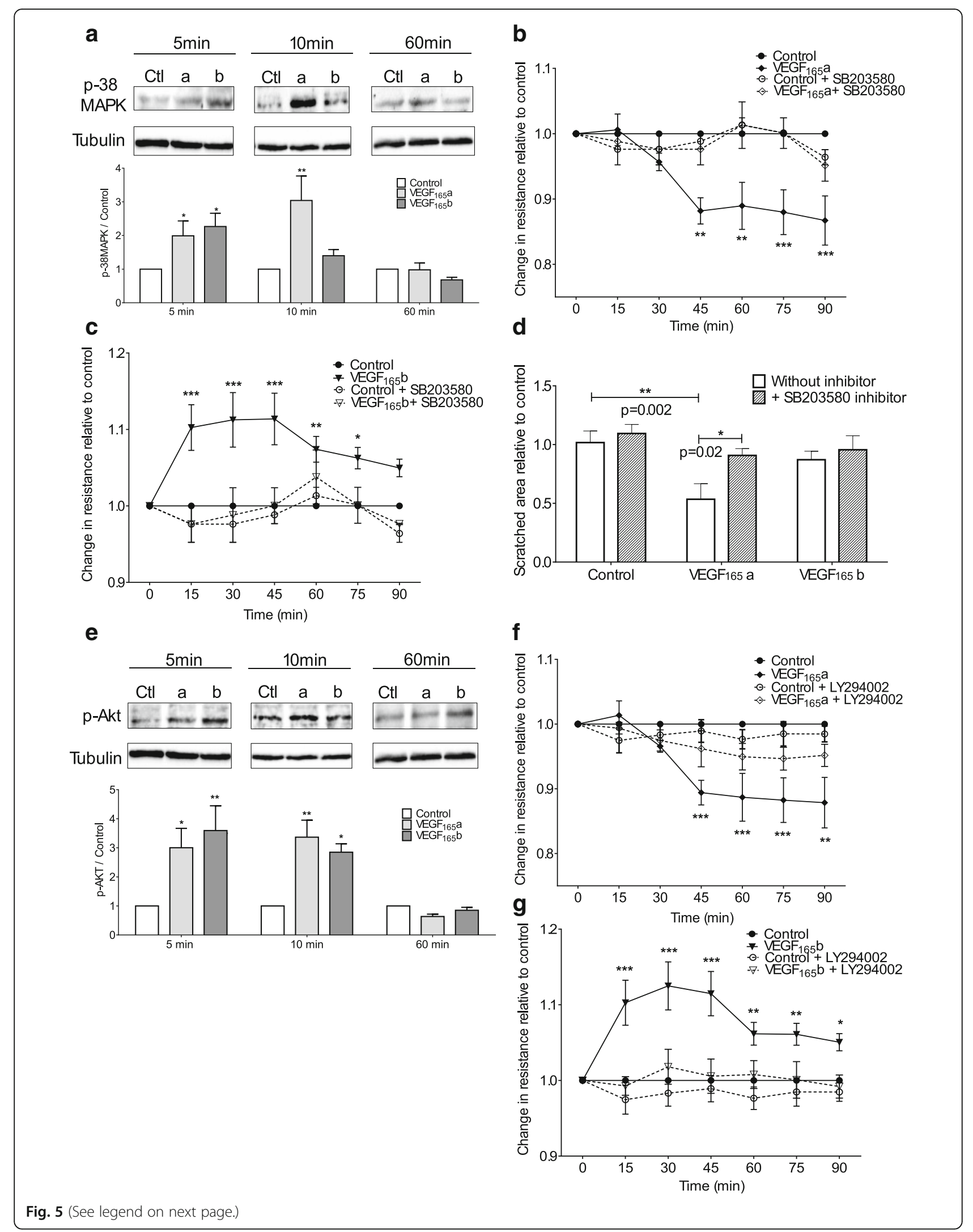


(See figure on previous page.)

Fig. $5 \mathrm{HPMEC}$ were stimulated with $20 \mathrm{ng} / \mathrm{ml}$ of $\mathrm{VEGF}_{165} \mathrm{a}, \mathrm{VEGF}_{165} \mathrm{~b}$ or without stimulation (Ctl/control). Representative western blots showing VEGF stimulation at 5, 10 and 60 min plus loading control (a-tubulin) with densitometry $(n=3)$. a Western blot of phosphorylated p-38MAPK in HPMEC. VEGF 165 a significantly increased phosphorylation of p-38MAPK at 5 and 10 min where VEGF ${ }_{165} \mathrm{~b}$ only induced increased phosphorylation at 5 min. b \& c: Measurement of HPMEC resistance by Endohm system. Dotted lines correspond to cell pre-incubated with p38 inhibitor SB203580. SB203580 inhibited the effect of VEGF ${ }_{165} \mathrm{a}$ (b) and the effect of $\mathrm{VEGF}_{165} \mathrm{~b}$ (c). $\mathbf{d}$ Graphs represent the mean of the scratched area for HPMEC treated with SB203580 inhibitor at $24 \mathrm{~h}$ relative to control. VEGF 165 a but not VEGF $165 \mathrm{~b}$ stimulation significantly diminished scratched area $(p=0.002)$ and was inhibited by SB203580 ( $p=0.02)$. e Western blot of phosphorylated AKT in HPMEC. VEGF 165 a and VEGF 165 b significantly increased phosphorylation of $p-A k t$ at 5 and 10 min. $\mathbf{f} \& \mathbf{g}$ Measurement of HPMEC resistance by Endohm system. Dotted lines correspond to cell pre-incubated with AKT inhibitor LY294002. LY294002 inhibited the effect of VEGF ${ }_{165}$ a $(\mathbf{f})$ and the effect of VEGF $165 \mathrm{~b}(\mathbf{g})$. Densitometry and scratch assay analysed by Kruskal-Wallis test with post hoc Dunn's analysis. TEER measurement analysed using two-way ANOVA and Bonferroni post-test. All data were plotted as mean \pm SEM $(n=3-6)$

cells stimulated by VEGF ${ }_{165}$ b (Fig. 6d). The inhibition of those effects induced by both VEGF 165 a and VEGF $_{165}$ b by L-NAME suggests that eNOS is not involved in the differential effect on permeability induced by these VEGF isoforms.

\section{Discussion}

The pulmonary endothelium is crucial to the regulation of the passage of solutes and molecules between the blood and the interstitial space of the lung, enabling close proximity of the vascular bed to the alveolar space for gaseous exchange to occur. Despite this, there is a very limited understanding of the mechanisms involved in the regulation of pulmonary endothelial cell (EC) barrier function integrity, which is so essential for maintaining this critical function of the lung.

Vascular endothelial growth factor (VEGF) was originally described as both an angiogenic and a permeability factor [39] and its effects have previously been studied using the human umbilical vein endothelial cell (HUVEC) as the archetypal EC. Large organ functional differences are reflected in the variability of endothelial cell junction structure and composition particularly relevant in the functional differences between the pulmonary and systemic circulation
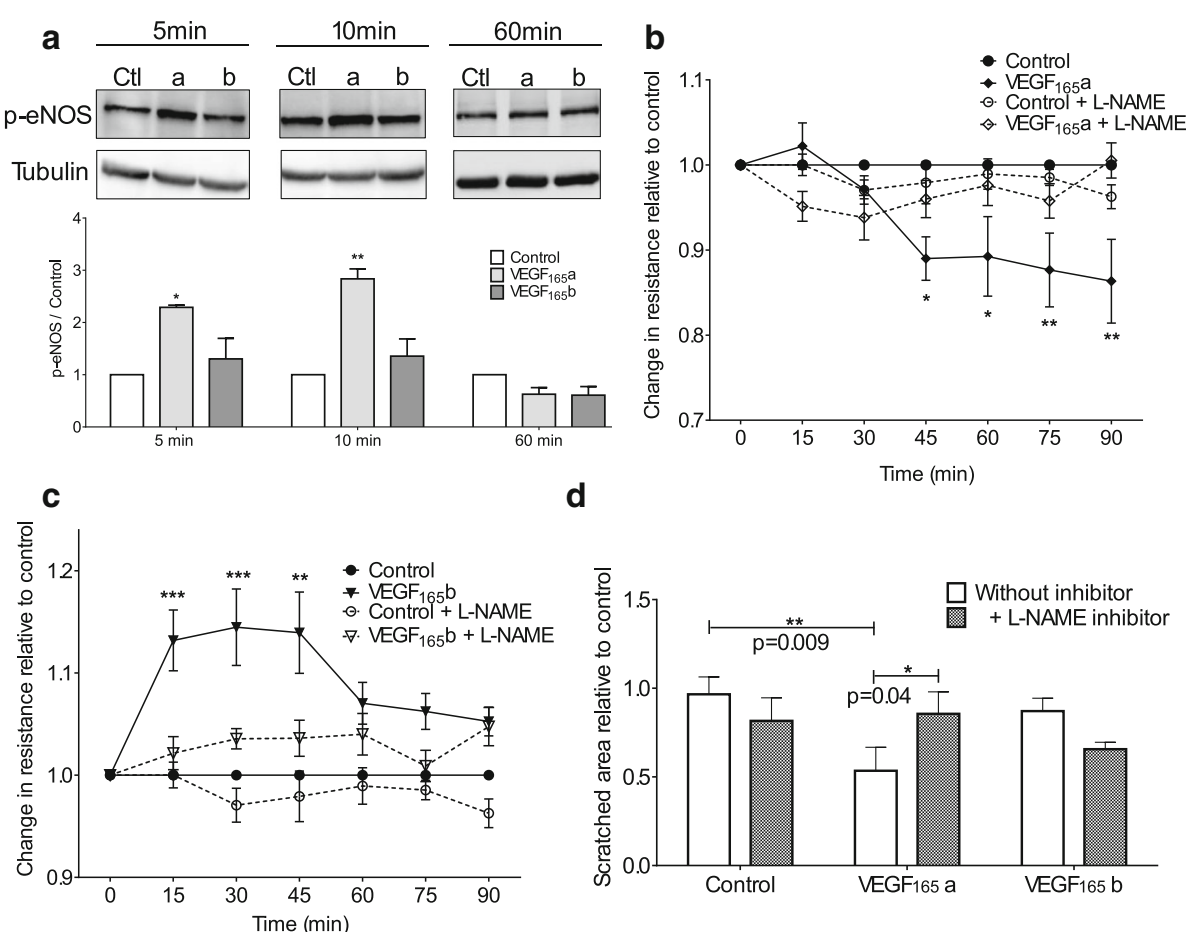

d

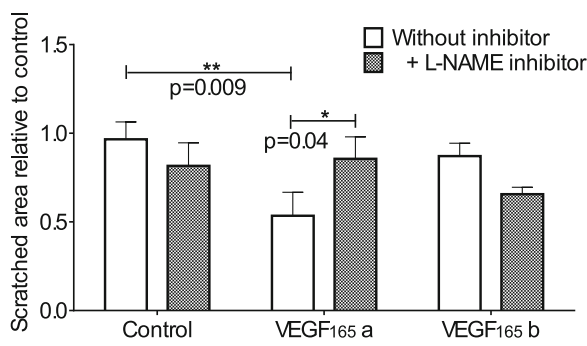

Fig. 6 a Representative Western blot of phosphorylated p-eNOS in HPMEC $(n=3)$. VEGF 165 a significantly increased phosphorylation of eNOS at 5 and 10 min in contrast with VEGF 165 b stimulation which did not induce any changes. b \& c Measurement of HPMEC resistance by Endohm system. Dotted lines correspond to cell pre-incubated with inhibitor. L-NAME inhibited the effect of VEGF 165 a (b) and the effect of VEGF 165 (c). $\mathbf{d}$ Graphs represent the mean of the scratched area for HPMEC treated with L-NAME inhibitor at $24 \mathrm{~h}$ relative to control. VEGF 165 a but not VEGF ${ }_{165} \mathrm{~b}$ stimulation significantly diminished scratched area $(p=0.009)$ and was inhibited by L-NAME $(p=0.04)$. Densitometry and scratch assay were analysed by Kruskal-Wallis test with post hoc Dunn's analysis. TEER measurement data were analysed using two-way ANOVA and Bonferroni post-test for multiple analysis. All data were plotted as mean \pm SEM $(n=3-6)$ 
[40, 41]. To explore our hypothesis and its relationship to previous clinical studies $(5,6)$ it was important to study the response of human pulmonary microvascular endothelial cell (HPMEC) to VEGF isoforms.

Among all the pathological processes involved in. ARDS increases in lung vessel permeability are critical and non-redundant [42]. The measurement of permeability in this study has been undertaken only in-vitro models with self-evident limitations [43]. Transport of plasma proteins, cell and solutes across monolayers occurs paracellularly via specialised endothelial cell-cell junctions, or transcellularly by special transport mechanism including transcytosis, via transcellular channels or cell membrane transporter proteins.

Two types of inter-endothelial junction are present in the endothelium, adherens and tight junctions, the former being dominant in most vascular beds. The integrity of the adherens junction is particularly critical for regulating paracellular permeability via homophilic adhesions between VE-cadherin molecules $[19,20]$. Disruptions of these domains lead to downstream events that result in organisational changes in the actin cytoskeleton [44]. The transcellular pathway is responsible for the transport of larger molecules such as albumin across endothelial cell monolayers, classically via transcellular pores associated with caveolae and lipid rafts [45]. Traditionally these pathways have been considered independent but there is now a body of evidence showing interdependence [46]. Following on from this, the in-vitro methods of measuring permeability that we have used, TEER (thought to reflect only paracellular permeability) and FITC-BSA (thought to only reflect transcellular mechanism) are recognised to have influences from crosstalk between both pathways [15].

We have demonstrated for the first time that VEGF $_{165} \mathrm{a}$ and VEGF $_{165} \mathrm{~b}$ induce differing effects on the permeability of pulmonary microvascular endothelial cells. Specifically, $V_{E G F}{ }_{165}$ a induced an increase and $\mathrm{VEGF}_{165} \mathrm{~b}$ a decrease in permeability. The receptor binding and dimerisation domains are intact in the $\mathrm{VEGF}_{\mathrm{xxx}} \mathrm{b}$ family of VEGF isoforms. However, in porcine aortic endothelial cells, $V_{E G F}{ }_{165} \mathrm{~b}$ has been shown to stimulate a unique pattern of VEGF-R2 tyrosine residue phosphorylation, contrasting with those activated by conventional isoforms suggesting activation of differing downstream signalling pathways in addition to partial agonist activity and changes in neuroplin-1 binding [22, 47, 48]. In this study, differing phosphorylation kinetics were clearly observed following stimulation by VEGF ${ }_{165} \mathrm{a}$ and $\mathrm{VEGF}_{165} \mathrm{~b}$ using what we considered to be physiologically relevant concentrations of VEGF.

The differential effects of VEGF ${ }_{165} \mathrm{a}$ and $\mathrm{VEGF}_{165} \mathrm{~b}$ on the vascular permeability in addition to those we have previously shown and published on proliferation in HPMEC (also repeated in the scratch experiments) and human alveolar epithelial cells offer a potential paradigm to explain the apparent compartmentalisation of VEGF between the alveolar and vascular space and the apparent disparity of data relating to the role of VEGF in ARDS [5, 6, 12].

We identified that $V_{E G F}$ 165 a and $V_{E G F}$ i65 $\mathrm{b}$ lead to differential functional outcomes with $\mathrm{VEGF}_{165}$ a increasing cell permeability in methods suggested to reflect both para and transcellular permeability and $V_{E G F}{ }_{165} \mathrm{~b}$ reducing paracellular permeability only. This suggested that the differences were due to divergence of signalling pathways and therefore potential targets for amelioration of outcome e.g. reducing permeability whilst preserving a pneumotropic effect. To verify this hypothesis, different protein inhibitors have been used to look at their effect on the change in resistance reflecting the paracellular permeability pathway of pulmonary microvascular ECs.

The VEGF $_{165}$ a signalling pathways have been studied extensively in HUVEC although studies in HPMEC are limited [41]. We chose to use inhibitors of pMEK, P38 MAPK, PI3 kinase and eNOS proteins as these proteins have been suggested to be involved in VEGF signalling pathways and look at both permeability and proliferation/ migration in an attempt to identify a divergence in functionality and thus an opportunity for selective inhibition.

The use of L-NAME (eNOS inhibitor) and LY294002 (PI3K inhibitor) on HPMEC inhibited the effect of both $\mathrm{VEGF}_{165} \mathrm{a}$ and $\mathrm{VEGF}_{165} \mathrm{~b}$. Being part of the same signalling pathway these results suggest that VEGF cell paracellular permeability involves the phosphoinositide 3-kinase-AKT pathway, which then further phosphorylates and activates endothelial nitric oxide synthase (eNOS) [49]. Also, the inhibition of pMEK and p38 MAPK did not affect VEGF isoforms activity on the proliferation and paracellular permeability pathway in HPMEC. In summary, the inhibitors chosen did not allow for the identification of specific differential pathways between $V_{E G F} F_{165}$ a and $V_{E G F} F_{165} b$. Further studies of other pathways are required in order to unravel the molecules responsible for the differential permeability effects of VEGF isoforms such as Src kinase pathway and its role in the regulation of endothelial-barrier integrity as demonstrated recently by Gao et al. [50].

\section{Conclusion}

HPMEC have specific signalling characteristics that are probably adaptations to the unique pulmonary environment. In the context of ARDS, VEGF (from the alveolus) may be a triggering component leading to further endothelial dysfunction and failure of the ACM. The data presented has shown that exposure of HPMEC to exogenous $V_{E G F}{ }_{165}$ a significantly increased endothelial cell monolayer permeability which would lead to failure 
of the ACM barrier function, of particular significance in the lung environment. On the other hand, depending on the isoforms present, VEGF may also be a protective agent, the data presented showing a decrease in permeability with $\mathrm{VEGF}_{165} \mathrm{~b}$ exposure. Further work will need to be undertaken to clearly identify the divergence in the permeability signalling pathway induced by both isoforms and the potential protective proprieties of $\mathrm{VEGF}_{165} \mathrm{~b}$.

\begin{abstract}
Abbreviations
${ }^{\circ} \mathrm{C}$ : Degrees celsius; ACM: Alveolar capillary membrane; AKT: AKT8 virus oncogene cellular homolog; ANOVA: Analysis of variance; ARDS: Acute respiratory distress syndrome; BSA: Bovine serum albumin; Ctl: Control; DAPI: 4,,6-diamidino-2-phenylindole; EC: Endothelial cell; ECIS: Electrical cell impedance system; eNOS: Endothelial nitric oxide synthase; EVOM: Epithelia voltohmmeter; FITC: Fluorescein isothiocyanate; HPMEC: Human pulmonary microvascular endothelial cell; HUVEC: Human umbilical vein endothelial cell; L-NAME: NG-Nitro-L-arginine Methyl Ester; MAPK: Mitogen-activated protein kinase; MEK: Mitogen/extracellular signal-regulated kinase; Min: Minutes: p38MAPK: p38 mitogen-activated protein kinase; PI3K: Phosphoinositide 3kinase; SDS-PAGE: Sodium dodecyl sulphate polyacrylamide gel electrophoresis; SEM: Standard error of the mean; SRC: V-scr sarcoma (Schimidt-Ruppin A-2) viral oncogene homolog; TEER: Transendothelial electrical resistance; Tyr: Tyrosin; UK: United Kingdom; USA: United States of America; VE-Cadherin: Vascular endothelial cadherin; VEGF: Vascular endothelial growth factor; VEGF-R1: Vascular endothelial growth factor receptor 1; VEGF-R2: Vascular endothelial growth factor -receptor 2; WB: Western blotting
\end{abstract}

\section{Acknowledgements}

Not applicable.

\section{Funding}

This study was funded by an unrestricted Novartis PhD Studentship to KO and a Welcome Clinical training fellowship to SL. The funding organisations had no role in the design of the study, collection, analysis, and interpretation of the data, or writing of the manuscript.

\section{Availability of data and materials}

All data generated during this study are included in this published article [and its supplementary information files].

\section{Authors' contributions}

$\mathrm{KO}, \mathrm{GIW}$ and $\mathrm{ABM}$ designed the experiments; $\mathrm{KO}$ and TB carried out experiments and collected data. CJ, SBO helped with analysis and interpretation of the data. $\mathrm{KO}, \mathrm{GIW}$ and $\mathrm{ABM}$ contributed to data analysis and prepared the manuscript.

\section{Competing interests}

The authors declare that they have no competing interests.

\section{Consent for publication}

Not applicable.

\section{Ethics approval and consent to participate}

Not applicable.

\section{Publisher's Note}

Springer Nature remains neutral with regard to jurisdictional claims in published maps and institutional affiliations.

\section{Author details}

'Academic Respiratory Unit, School of Clinical Sciences, University of Bristol, Bristol, UK. ${ }^{2}$ Bristol Renal, School of Clinical Sciences, University of Bristol, Bistol, UK.
Received: 20 February 2017 Accepted: 30 May 2017

Published online: 02 June 2017

\section{References}

1. Abadie Y, Bregeon F, Papazian L, Lange F, Chailley-Heu B, Thomas P, Duvaldestin P, Adnot S, Maitre B, Delclaux C. Decreased VEGF concentration in lung tissue and vascular injury during ARDS. Eur Respir J. 2005:25:139-46.

2. Maitre B, Boussat S, Jean D, Gouge M, Brochard L, Housset B, Adnot S, Delclaux C. Vascular endothelial growth factor synthesis in the acute phase of experimental and clinical lung injury. Eur Respir J. 2001;18:100-6.

3. Kaner RJ, Ladetto JV, Singh R, Fukuda N, Matthay MA, Crystal RG. Lung overexpression of the vascular endothelial growth factor gene induces pulmonary edema. Am J Respir Cell Mol Biol. 2000;22:657-64.

4. Kaner RJ, Crystal RG. Compartmentalization of vascular endothelial growth factor to the epithelial surface of the human lung. Mol Med. 2001;7:240-6.

5. Thickett DR, Armstrong L, Millar AB. A role for vascular endothelial growth factor in acute and resolving lung injury. Am J Respir Crit Care Med. 2002; 166:1332-7.

6. Thickett DR, Armstrong L, Christie SJ, Millar AB. Vascular endothelial growth factor may contribute to increased vascular permeability in acute respiratory distress syndrome. Am J Respir Crit Care Med. 2001;164:1601-5.

7. Koch S, Tuques S, Li X, Gualandi L, Claesson-Welsh L. Signal transduction by vascular endothelial growth factor receptors. Biochem J. 2011;437:169-83.

8. Houck KA, Ferrara N, Winer J, Cachianes G, Li B, Leung DW. The vascular endothelial growth factor family: identification of a fourth molecular species and characterization of alternative splicing of RNA. Mol Endocrinol. 1991:5: 1806-14.

9. Harper SJ, Bates DO. VEGF-a splicing: the key to anti-angiogenic therapeutics? Nat Rev Cancer. 2008:8:880-7.

10. Medford AR, Ibrahim NB, Millar AB. Vascular endothelial growth factor receptor and coreceptor expression in human acute respiratory distress syndrome. J Crit Care. 2009;24:236-42.

11. Bates DO, Cui TG, Doughty JM, Winkler M, Sugiono M, Shields JD, Peat D, Gillatt D, Harper SJ. VEGF165b, an inhibitory splice variant of vascular endothelial growth factor, is down-regulated in renal cell carcinoma. Cancer Res. 2002;62:4123-31.

12. Varet J, Douglas SK, Gilmartin L, Medford AR, Bates DO, Harper SJ, Millar AB. VEGF in the lung: a role for novel isoforms. Am J Physiol Lung Cell Mol Physiol. 2010;298:L768-774.

13. Bevan HS, van den Akker NM, Qiu Y, Polman JA, Foster RR, Yem J, Nishikawa A, Satchell SC, Harper SJ, Gittenberger-de Groot AC, Bates DO. The alternatively spliced anti-angiogenic family of VEGF isoforms VEGFxxxb in human kidney development. Nephron Physiol. 2008;110:p57-67.

14. Van Nieuw Amerongen GP, Van Hinsbergh VW. Determination of the endothelial barrier function in vitro. Methods Mol Biol. 1999;96:183-9.

15. Wegener J, Seebach J. Experimental tools to monitor the dynamics of endothelial barrier function: a survey of in vitro approaches. Cell Tissue Res. 2014:355:485-514.

16. Cereijido M, Gonzalez-Mariscal L, Contreras RG, Gallardo JM, Garcia-Villegas R, Valdes J. The making of a tight junction. J Cell Sci Suppl. 1993:17:127-32.

17. Wegener J, Sieber M, Galla HJ. Impedance analysis of epithelial and endothelial cell monolayers cultured on gold surfaces. J Biochem Biophys Methods. 1996:32:151-70.

18. Forster C. Tight junctions and the modulation of barrier function in disease. Histochem Cell Biol. 2008:130:55-70.

19. Wallez Y, Huber P. Endothelial adherens and tight junctions in vascular homeostasis, inflammation and angiogenesis. Biochim Biophys Acta. 1778; 2008:794-809

20. Esser S, Lampugnani MG, Corada M, Dejana E, Risau W. Vascular endothelial growth factor induces VE-cadherin tyrosine phosphorylation in endothelial cells. J Cell Sci. 1998:111(Pt 13):1853-65.

21. Smith GA, Fearnley GW, Tomlinson DC, Harrison MA, Ponnambalam S. The cellular response to vascular endothelial growth factors requires co-ordinated signal transduction, trafficking and proteolysis. Biosci Rep. 2015;35:e00253.

22. Kawamura H, Li X, Harper SJ, Bates DO, Claesson-Welsh L. Vascular endothelial growth factor (VEGF)-A165b is a weak in vitro agonist for VEGF receptor-2 due to lack of coreceptor binding and deficient regulation of kinase activity. Cancer Res. 2008:68:4683-92.

23. Takahashi T, Ueno H, Shibuya M. VEGF activates protein kinase C-dependent, but Ras-independent Raf-MEK-MAP kinase pathway for DNA synthesis in primary endothelial cells. Oncogene. 1999;18:2221-30. 
24. Dayanir V, Meyer RD, Lashkari K, Rahimi N. Identification of tyrosine residues in vascular endothelial growth factor receptor-2/FLK-1 involved in activation of phosphatidylinositol 3-kinase and cell proliferation. J Biol Chem. 2001;276: 17686-92.

25. Zahm JM, Kaplan H, Herard AL, Doriot F, Pierrot D, Somelette P, Puchelle E. Cell migration and proliferation during the in vitro wound repair of the respiratory epithelium. Cell Motil Cytoskeleton. 1997;37:33-43.

26. Liang CC, Park AY, Guan JL. In vitro scratch assay: a convenient and inexpensive method for analysis of cell migration in vitro. Nat Protoc. 2007;2:329-33.

27. Zachary I. VEGF signalling: integration and multi-tasking in endothelial cell biology. Biochem Soc Trans. 2003;31:1171-7.

28. Crews CM, Alessandrini A, Erikson RL. The primary structure of MEK, a protein kinase that phosphorylates the ERK gene product. Science. 1992; 258:478-80.

29. Issbrucker K, Marti HH, Hippenstiel S, Springmann G, Voswinckel R, Gaumann A, Breier G, Drexler HC, Suttorp N, Clauss M. p38 MAP kinase-a molecular switch between VEGF-induced angiogenesis and vascular hyperpermeability. FASEB J. 2003;17:262-4.

30. Davies SP, Reddy H, Caivano M, Cohen P. Specificity and mechanism of action of some commonly used protein kinase inhibitors. Biochem J. 2000; 351:95-105.

31. Lamalice L, Houle F, Huot J. Phosphorylation of Tyr1214 within VEGFR-2 triggers the recruitment of Nck and activation of Fyn leading to SAPK2/p38 activation and endothelial cell migration in response to VEGF. J Biol Chem. 2006;281:34009-20.

32. Song G, Ouyang G, Bao S. The activation of Akt/PKB signaling pathway and cell survival. J Cell Mol Med. 2005;9:59-71.

33. Fulton D, Gratton JP, McCabe TJ, Fontana J, Fujio Y, Walsh K, Franke TF, Papapetropoulos A, Sessa WC. Regulation of endothelium-derived nitric oxide production by the protein kinase Akt. Nature. 1999;399:597-601.

34. Bondar VM, Sweeney-Gotsch B, Andreeff M, Mills GB, McConkey DJ. Inhibition of the phosphatidylinositol 3'-kinase-AKT pathway induces apoptosis in pancreatic carcinoma cells in vitro and in vivo. Mol Cancer Ther. 2002;1:989-97.

35. Vlahos CJ, Matter WF, Hui KY, Brown RF. A specific inhibitor of phosphatidylinositol 3-kinase, 2-(4-morpholinyl)-8-phenyl-4H-1-benzopyran-4one (LY294002). J Biol Chem. 1994;269:5241-8.

36. Fukumura D, Gohongi T, Kadambi A, Izumi Y, Ang J, Yun CO, Buerk DG, Huang PL, Jain RK. Predominant role of endothelial nitric oxide synthase in vascular endothelial growth factor-induced angiogenesis and vascular permeability. Proc Natl Acad Sci U S A. 2001;98:2604-9.

37. Hatakeyama T, Pappas PJ, Hobson 2nd RW, Boric MP, Sessa WC, Duran WN. Endothelial nitric oxide synthase regulates microvascular hyperpermeability in vivo. J Physiol. 2006:574:275-81.

38. Kubes P, Suzuki M, Granger DN. Nitric oxide: an endogenous modulator of leukocyte adhesion. Proc Natl Acad Sci U S A. 1991;88:4651-5.

39. Ferrara N, Gerber HP, LeCouter J. The biology of VEGF and its receptors. Nat Med. 2003:9:669-76

40. Aird WC. Endothelial cell heterogeneity. Cold Spring Harb Perspect Med 2012;2:a006429.

41. Becker PM, Verin AD, Booth MA, Liu F, Birukova A, Garcia JG. Differential regulation of diverse physiological responses to VEGF in pulmonary endothelial cells. Am J Physiol Lung Cell Mol Physiol. 2001;281:L1500-1511.

42. Herold S, Gabrielli NM, Vadasz I. Novel concepts of acute lung injury and alveolar-capillary barrier dysfunction. Am J Physiol Lung Cell Mol Physiol. 2013;305:L665-681.

43. Bates DO. Vascular endothelial growth factors and vascular permeability. Cardiovasc Res. 2010;87:262-71.

44. Giannotta M, Trani M, Dejana E. VE-cadherin and endothelial adherens junctions: active guardians of vascular integrity. Dev Cell. 2013;26:441-54.

45. Garrido-Urbani S, Bradfield PF, Lee BP, Imhof BA. Vascular and epithelial junctions: a barrier for leucocyte migration. Biochem Soc Trans. 2008;36:203-11.

46. Komarova Y, Malik AB. Regulation of endothelial permeability via paracellular and transcellular transport pathways. Annu Rev Physiol. 2010;72:463-93.

47. Cebe Suarez S, Pieren M, Cariolato L, Arn S, Hoffmann U, Bogucki A, Manlius C. Wood J, Ballmer-Hofer K. A VEGF-a splice variant defective for heparan sulfate and neuropilin-1 binding shows attenuated signaling through VEGFR-2. Cell Mol Life Sci. 2006:63:2067-77.

48. Becker PM, Waltenberger J, Yachechko R, Mirzapoiazova T, Sham JS, Lee CG, Elias JA, Verin AD. Neuropilin-1 regulates vascular endothelial growth factormediated endothelial permeability. Circ Res. 2005;96:1257-65.
49. Zachary I, Gliki G. Signaling transduction mechanisms mediating biological actions of the vascular endothelial growth factor family. Cardiovasc Res. 2001:49:568-81.

50. Gao F, Sabbineni H, Artham S, Somanath PR. Modulation of long-term endothelial-barrier integrity is conditional to the cross-talk between Akt and Src signaling. J Cell Physiol. 2017. doi:10.1002/jcp.25791. [Epub ahead of print]

\section{Submit your next manuscript to BioMed Central and we will help you at every step:}

- We accept pre-submission inquiries

- Our selector tool helps you to find the most relevant journal

- We provide round the clock customer support

- Convenient online submission

- Thorough peer review

- Inclusion in PubMed and all major indexing services

- Maximum visibility for your research

Submit your manuscript at www.biomedcentral.com/submit

) Biomed Central 